REVISTA

dela

CEPA

NUMERO EO

ACOBTO 1993

SANTIAGO DE CHILE

ANIBAL PINTO

Director

EUGENIO LAHERA

Secretario Técnico

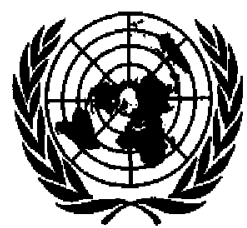

NACIONES UNIDAS 
Jacobo Schatan

La Integración reglonal en los años noventa

Gert Rosenthal

El resurgImiento de la Integración y el legado de Prebisch

José Manuel Salazar

La liberallzación comerclal en América Latına

Manuel Agosin y Ricardo Ffrench-Davis

Crecimiento, crisls y viraje estratéglco

Joseph Ramos

Falla del mercado y política tecnológlca

Jorge M. Katz

Crisis monetarla, dolarlzación y tipo de camblo

Paulo Nogueira Batista Jr.

El financiamlento en los procesos de descentralización

Dolores Marta Rufián Lizana

Migración intrarregional de mano de obra calificada

Jorge Martinez

Clencias sociales y realidad soclal en Centroamérlca

Andrés Pérez

Formación histórlca de la estratificación soclal en América Latina

Enzo Falefto

Estructura socioeconómica y comportamlento colectivo

Rodrigo Baño

Clasiflcaclón por autores y temática de los artículos publicados

en la Revista de la CEPAL, del número 1 al 50

Orlentaciones para los colaboradores de la Revista de la CEPAL 


\section{La liberalización comercial en América Latina}

\section{Manuel R. Agosin Rlcardo Ffrench-Davis}

Profesor, Departamento de Economia de la Universidad de Chile y Jefe de Programa, UNCTAD, Ginebra.

Asesor Regional Principal de la CEPAL en materia de Politicas Económicas.
Las estrategias de desarrollo de la mayoría de los países latinoamericanos han experimentado un vuelco notable en los últimos años. Este vuelco se ha traducido en una creciente neutralidad de los incentivos que se otorgan en la aplicación de la política comercial, con el objetivo de dar prioridad al mercado como mecanismo asignador de recursos y con la expectativa de que oriente en mayor medida al aparato productivo hacia las exportaciones. Este artículo reseña tales cambios y, al hacer una evaluación de los resultados ya obtenidos, y de la coherencia de las políticas, señala que su impacto sobre el crecimiento económico y la transformación productiva ha sido poco auspicioso hasta el momento. En general, ni la formación de capital ni la productividad global han registrado un desempeño satisfactorio. El artículo contiene recomendaciones sobre diversas medidas que pueden complementar las políticas adoptadas a fin de impulsar una apertura que favorezca tanto la transformación productiva como el desarrollo. 
I

\section{¿Hacia una nueva}

\section{estrategia de desarrollo?}

En los últimos años, un gran número de países de América Latina se ha embarcado en procesos de liberalización comercial. Este artículo pasa revista al vuelco que esto ha significado en materia de política comercial, así como a los resultados logrados y previstos, y entrega algunas recomendaciones de carácter preliminar sobre medidas complementarias.

La primera experiencia sostenida de liberalización comercial fue la de Chile, país que comenzo en los años setenta un proceso que, hacia fines de esa década, haría de su economía una de las más abiertas del mundo.

A mediados de los años ochenta se vislumbraba ya una tendencia a un giro radical de la estrategia de desarrollo y de las políticas que la acompañaban, luego de más de medio siglo de proteccionismo. Ya en 1983 Costa Rica había iniciado un tránsito gradual desde un modelo de sustitución de importaciones a nivel nacional y centroamericano hacia uno de inserción más dinámica en los mercados internacionales, dando primacía a los mercados extrarregionales. Y luego, en 1985, Bolivia y México habían iniciado liberalizaciones relativamente rápidas.

Al comenzar la década de 1990, varios países se agregaron a esta tendencia, entre ellos Argentina, Brasil, Perú y Venezuela. Incluso Colombia, que en 1990 había adoptado un programa de apertura gradual que se llevaría a cabo en cuatro años, a mediados de 1991 decidió acelerar la liberalización y completarla en 1992. Con diferentes grados de celeridad, los países de la región habían dado un viraje histórico.

Explícita o implícitamente, cada país debió decidir cómo hacer la liberalización, qué liberalizar y qué no liberalizar, cuánto, en qué secuencia, y qué otras políticas adoptar para lograr una liberalización que contribuyera al desarrollo (véase más adelante la sección II). En este artículo se pretende dar algunas respuestas preliminares a tales pregun-

Los autores agradecen los valiosos comentarios de O. Altimir, H. Assael, R. Baumann, W. Fritsch, J. Katz, C. Massad, W. Peres, J. Ros, $\mathrm{O}$. Rosales y D. Titelman, así como la colaboración de M.A. Larach. tas, sobre la base de las experiencias recientes de América Latina.

El examen que se hace más adelante, (sección III), de una parte de la voluminosa literatura sobre las economías exportadoras de Asia (la Républica de Corea, la provincia china de Taiwán y, más recientemente, Indonesia, Malasia y Tailandia) sirve para contrastar esas experiencias más recientes de América Latina con otras de más larga duración y de corte muy distinto. La mayor diferencia entre las liberalizaciones en países latinoamericanos y las aperturas en el Asia radica en que, mientras la mayoría de los ensayos liberalizadores en América Latina se realizaron en forma brusca y con un Estado pasivo, en las economías asiáticas la apertura fue un largo proceso, liderado por el Estado, de construcción de un aparato productivo orientado hacia los mercados internacionales. ${ }^{1}$ Cuando se liberalizaron las importaciones en el Asia, la transformación estructural ya había sido lograda y las exportaciones exhibían un prolongado dinamismo. A ello se agregaba, en general, una situación macroeconómica equilibrada y una inversión notoriamente más alta. En contraste, en América Latina las liberalizaciones drásticas de las importaciones se llevaron a cabo al inicio de las estrategias de internacionatización, y con frecuencia coincidieron con procesos de estabilización y con una baja tasa de formación de capital.

Algunos de los elementos claves de los programas de reforma se examinan más adelante (sección IV) a la luz de los requerimientos de una apertura dinamizadora del desarrollo de largo plazo. Es evidente que en el mundo actual la competitividad internacional y la inserción más dinámica en los mercados internacionales se han convertido en

\footnotetext{
${ }^{1}$ Adoptamos aquí la diferencia que establecen Damill y Keifman (1992) entre "apertura" y "liberalización". El primer concepto se aplica al conjunto de políticas para orientar a la economía hacia los mercados internacionales, en un proceso liderado por las exportaciones. El último se refierc solamente al desmantelamiento de la protección y de otros controles gubernamentales, en un proceso liderado por las importaciones.
} 
condicion indispensable para lograr un desarrollo sostenido. Por lo tanto, era necesario reducir las restricciones a la importación. Las antiguas políticas de proteccionismo a ultranza de cualquier bien que pueda producirse internamente constituyen un obstáculo al desarrollo.

El problema fundamental de las políticas proteccionistas del pasado era que, al final, no se sabía qué se estaba incentivando ni con qué propósitos (Ffrench-Davis, 1986). Como anotan Fritsch y Franco (1993, p. 32), la protección generalizada puede terminar no protegiendo cosa alguna en particular, amén de ser muy costosa. Las políticas proteccionistas pasadas, tanto en América Latina como en otras regiones, tendieron a ser aprovechadas por intereses privados que buscaban ingresos fáciles. En muchos casos no hubo beneficios sociales evidentes, y se tendió a constituir estructuras industriales poco competitivas en el mercado internacional que siguieron dependiendo indefinidamente de la protección gubernamental. Pero también es necesario reconocer que dichos esquemas permitieron la aparición de sectores industriales que han sido la base de un posterior desarrollo orientado en mayor medida que antes hacia la competitividad internacional.

Para que una reforma comercial sea exitosa es preciso que el valor agregado por la creación de nuevas actividades sea mayor que el "desagregado" por la destrucción de ellas, lo que implica que el aumento de las exportaciones sea más significativo que la baja en la sustitución de importaciones; ${ }^{2}$ que las exportaciones arrastren positivamente al resto de la economía, lo que está asociado a la diversificación y valor agregado que ellas tengan, y que la competitividad internacional se logre con aumentos continuos de la productividad en vez de salarios bajos y subsidios o exenciones tributarias crecientes.

Por eso se hace indispensable que la apertura evite la destrucción indiscriminada de la capacidad instalada existente y que permita una efectiva reconversión productiva; que vaya acompañada de un cambio sostenido y creíble de los precios relativos a favor de la produccion de bienes exportables, y que perfeccione o cree los mercados e instituciones requeridos para la mejora persistente de la productividad, a través de la capacitación laboral, el mejoramiento de la infraestructura, los incentivos a la innovación tecnológica, el desarrollo de un mercado de capitales de largo plazo o canalizado hacia la inversión productiva, y el fortalecimiento de la capacidad para negociar el acceso a mercados externos.

En general, este criterio no ha primado en los países latinoamericanos que se han lanzado a la liberalización comercial, ya que la mayoría de ellos lo ha hecho sin elaborar una estrategia de apertura. Este enfoque muestra imperfecciones graves en tres campos decisivos. Primero, las aperturas unilaterales sin contraparte, que tienen sentido en una economía mundial abierta, dinámica y competitiva, lo tienen menos en una economía en la cual el proteccionismo sigue activo, el comercio crece lentamente, y hay fuerte tendencia a la formación de bloques comerciales regionales. Segundo, el proceso descansa en ventajas comparativas estáticas y ganancias de corto plazo en la asignación de recursos, pero es vulnerable si se concentra en rubros con mercados menos dinámicos y con menos innovación tecnológica. Tercero, en los mercados financieros y en la cuenta de capitales de la balanza de pagos, las nuevas orientaciones hacia la desregulacion del mercado han entorpecido la reasignación de recursos que se buscaba a través de la liberalización comercial, al propiciar (en las condiciones imperantes en los ańos noventa) marcadas apreciaciones cambiarias y altas tasas de interés. Ellas desincentivan la inversión productiva requerida para alcanzar la transformación estructural y, al mismo tiempo, concentran los recursos en inversiones puramente financieras.

\footnotetext{
${ }^{2}$ Esto no significa que la sustitución de importaciones deba ser desechada. Mientras más grande sea el mercado nacional, mayor será el ámbito potencial de la sustitución de importaciones. Ello se refleja en que las exportaciones de países como Estados Unidos y Japón sólo representan entre 10 y 15 por ciento de su PIB, respectivamente. Lo que es novedoso en la nueva estrategia de desarrollo
}

que se está perfilando es la insistencia en que las empresas productoras de bienes y servicios, ya sea para los mercados nacionales o para los internacionales, deben tornarse cada vez mús competitivas durante el período de aprendizaje. Esto se logra, en parte, con la exposición a la competencia externa y el cumplimiento de metas de exportación, inversión y desarrollo tecnológico. 


\section{II}

\section{Las liberalizaciones}

\section{comerciales en América Latina}

Las reformas comerciales liberalizadoras han sido bastante generalizadas en la región en años recientes (cuadro 1). Ocho de los nueve países incluidos en el cuadro - la excepción fue Costa Rica-introdujeron reformas que pueden catalogarse de drásticas $\mathrm{y}$ abruptas. En siete de los ocho países —en este caso la excepción fue Chile- la liberalización de las importaciones se llevó a cabo en un período de dos o tres años (1989-1990 a 1992-1993). En Argentina la mayor parte de esa liberalización se efectuó en abril de 1991. En Chile, el proceso tomo cinco affos y medio (desde fines de 1973 hasta mediados de 1979).

CUADRO 1

América Latina (nueve paises): Resumen del proceso de apertura comerclal

\begin{tabular}{|c|c|c|c|c|c|c|c|c|c|}
\hline \multirow[t]{2}{*}{$\mathrm{Pals}$} & \multirow{2}{*}{$\begin{array}{l}\text { Inicio del } \\
\text { programa } \\
\text { de libera- } \\
\text { lizacion }\end{array}$} & \multicolumn{2}{|c|}{ Arancel máximo } & \multicolumn{2}{|c|}{$\begin{array}{l}\text { Número de tramos } \\
\text { arancelarios }\end{array}$} & \multicolumn{2}{|c|}{ Arancel promedio } & \multirow[t]{2}{*}{ Barterns no arancelarias } & \multirow{2}{*}{$\begin{array}{l}\text { Variación } \\
\text { del tipo de } \\
\text { cambio real }\end{array}$} \\
\hline & & Inicial & $\begin{array}{l}\text { A fines } \\
\text { de } 1992\end{array}$ & Inicial & $\begin{array}{l}\text { A fines } \\
\text { de } 1992\end{array}$ & Inicial & $\begin{array}{l}\text { A fines } \\
\text { de } 1992\end{array}$ & & \\
\hline Argentina ${ }^{b}$ & 1989 & 65 & 30 & & 8 & $39^{2}$ & $15^{\mathrm{c}}$ & $\begin{array}{l}\text { En } 1988 \text { el valor de la producción industrial sujeto a } \\
\text { restriccion se redujo de } 62 \% \text { a } 18 \% \text {. En } 1989-1991 \\
\text { se eliminaron las restricciones no arancelarias, los } \\
\text { derechos adicionales transitorios y los derechos } \\
\text { especificos. }\end{array}$ & -40 \\
\hline Bolivia & 1985 & 150 & 10 & & 2 & $12^{\mathrm{d}}$ & $7^{d}$ & $\begin{array}{l}\text { Con pocas excepciones, se abolieron todas las } \\
\text { prohibiciones y requisitos de licencias a la } \\
\text { importación. }\end{array}$ & 134 \\
\hline Brasil & 1990 & 105 & 35 & 29 & 7 & $32^{e}$ & $21^{\mathrm{e}}$ & $\begin{array}{l}\text { En } 1990 \text { se elimino la lista de productos importados } \\
\text { prohibidos y los requisitos de licencia previa. } \\
\text { No obstante, se mantendrán las exigencias sobre } \\
\text { contenido nacional para bienes intermedios y de capital. }\end{array}$ & 31 \\
\hline Colombia $^{\mathrm{b}}$ & 1990 & 100 & 20 & 14 & 4 & $44^{d}$ & $12^{d}$ & $\begin{array}{l}\text { Las restricciones de licencias previas fueron eliminarlas } \\
\text { casi en su totalidad a fines de } 1990 \text {. }\end{array}$ & 1 \\
\hline Costa Rica & 1986 & 100 & 27 & & & $27^{*}$ & $20^{e}$ & $\begin{array}{l}\text { Gradual eliminacion de permisos de importación y otras } \\
\text { restricciones en el perfodo } 1990-1994 \text {. }\end{array}$ & 4 \\
\hline \multirow[t]{2}{*}{ Chile $^{f}$} & 1973 & 220 & 10 & 57 & 1 & $94^{\circ}$ & $10^{e}$ & $\begin{array}{l}\text { En la decada de } 1970 \text { se eliminaron las restricciones } \\
\text { cuantitativas a la importación }\end{array}$ & -10 \\
\hline & 1985 & 35 & 11 & 1 & 1 & $35^{\circ}$ & $11^{\circ}$ & $\begin{array}{l}\text { Se reintrodujeron bandas de precios y se establecio } \\
\text { on sistema antidumping. }\end{array}$ & 0 \\
\hline México & 1985 & 100 & 20 & 10 & 3 & $24^{\mathrm{c}}$ & $12^{\mathrm{c}}$ & $\begin{array}{l}\text { Se redujo la cobertura de los permisos de importación } \\
\text { sobre la produccion de } 92 \% \text { en junio de } 1985 \text { a } 18 \% \\
\text { en diciembre de } 1990 \text { y se eliminaron los precios } \\
\text { oficiales de importación. }\end{array}$ & -9 \\
\hline Perú $^{b}$ & 1990 & 108 & 25 & 56 & 2 & $66^{\mathrm{e}}$ & $18^{\mathrm{e}}$ & $\begin{array}{l}\text { En septiembre de } 1990 \text { se eliminaron las licencias, los } \\
\text { controles y las autorizaciones de importación, las cuotas } \\
\text { y las prohibiciones. }\end{array}$ & -21 \\
\hline Venezuela & 1989 & 135 & 20 & 41 & 4 & $35^{d}$ & $10^{d}$ & $\begin{array}{l}\text { Se redujo el número de rubros sujetos a restricciones de } \\
2200 \text { en } 1988 \text { a } 200 \text { en la actualidad. Se eliminaron los } \\
\text { derechos específicos que en algunos casos llevaban } \\
\text { el arancel máximo a } 940 \% \text { antes de aplicarse el programa } \\
\text { de liberalización. }\end{array}$ & 7 \\
\hline
\end{tabular}

Fuente: CEPAL, sobre la base de cifras nacionales.

a Desde el año inicial del programa de liberalización hasta 1992. Se ha utilizado el tipo de cambio para las exportaciones.

bos aranceles incluyen sobretasas.

c Ponderado por la producción interna.

d Ponderado por las importaciones.

- Promedio simple sobre la base de posiciones arancelarias.

f La primera liberalización comercial en Chile se completó en 1979. El arancel uniforme de $10 \%$ rigió hasta 1982 . Por lo tanto, la primera fila se refiere a la información para ese período (1973-82). La segunda fila da información acerca de la reducción del arancel de importación, el que luego de elevarse a 35\% en 1984 , se redujo sucesivamerte a $20 \%$ (1985), $15 \%$ (1988) y $11 \%$ (1991). 
En mayor o menor medida, en todos los casos hubo desmantelamiento de las restricciones cuantitativas y una rebaja considerable de los aranceles. En general, se dio un cambio apreciable respecto de la protección arancelaria vigente antes de las reformas, y disminuyó marcadamente la dispersión de la protección efectiva. No obstante, ningún país ha adoptado un arancel cero, y sólo Chile tiene un arancel uniforme, situado ahora en $11 \%$. Bolivia le sigue de cerca, al haber establecido sólo dos tramos con un máximo de $10 \%$. Todos los otros países tienen una gama de aranceles con tasas máximas de entre 20 y $40 \%$, y tasas medias de entre 10 y $20 \%$. Estas tendencias en las políticas comerciales de la región se han complementado con un movimiento hacia la celebración de acuerdos bilaterales o multilaterales de libre comercio que cubren un amplio espectro del universo arancelario y no se limitan a la desgravación de productos individuales (Lahera, 1992). ${ }^{3}$

En varios de los países de la región, la liberalización comercial ha ido acompañada de una liberalización de la cuenta de capitales de la balanza de pagos. En las condiciones imperantes desde comienzos de los años noventa, cuando los mercados internacionales de capital volvieron a evaluar positivamente a los países de América Latina, la liberalización de la cuenta de capitales ha promovido apreciaciones cambiarias importantes (Calvo, Leiderman y Reinhart, 1993; CEPAL, 1992a), en circunstancias en que la reforma comercial hacía imperativo lograr una depreciacion. Algunos países (Chile y Colombia) han sido más exitosos que otros en resistir las tendencias a la apreciación, pero para ello han debido recurrir a controles cambiarios y a otras medidas heterodoxas de "ingeniería financiera".

A continuación examinaremos las reformas recientes de tres países de la región, situándolas en el marco analítico que se expone en la primera parte de la sección. Se trata de los tres países donde las reformas se han mantenido por un tiempo suficientemente

\footnotetext{
${ }^{3}$ Hasta junio de 1990 predominaba ostensiblemente la opinión de que los acuerdos de integración debían ser de alcance parcial, muy limitado, al estilo del vigente en la Asociación Latinoamericana de Integración (ALADI) en ese tiempo. Según el enfoque analítico predominante, los bloques comerciales eran ineficientes y un obstáculo al comercio mundial. La Iniciativa para las Américas del Presidente Bush cambió radicalmente esa concepción. Parecen haberse olvidado absolutamente las preocupaciones respecto de la desviación de comercio.

${ }^{4}$ Sobre el caso de Chile, véase Agosint, Fuentes y Letelier (1993); y sobre las medidas recientes de Colombia para evitar la apreciación cambiaria, véase Cárdenas y Barrera (1993).
}

largo como para que sus efectos se reflejen en resultados económicos (Chile, México y Bolivia), lo que permite esbozar una evaluación de su impacto sobre el crecimiento y la inversión.

\section{El marco analítlco de la estrategla de inser- clón Internacional}

En general, las reformas comerciales se insertan en procesos amplios de cambio, que otorgan a la competitividad internacional y a las exportaciones un papel protagónico. El instrumento central de la reforma ha sido la liberalización, más o menos indiscriminada y rápida, de las importaciones. Con ella se busca exponer a la competencia externa a los productores de bienes importables, frecuentemente beneficiados hasta entonces con una fuerte protección. Se espera que ésta los lleve a mejorar la productividad, reduciendo la ineficiencia, incorporando nuevas tecnologías y aumentando la especialización. Los productores que no se adapten a la competencia externa serán desplazados del mercado, y los recursos que liberen se absorberán con rapidez, principalmente en la producción de rubros exportables.

Las exportaciones se ven incentivadas, en forma indirecta, por el abaratamiento y la ampliación del espectro de insumos importables a los que se puede acceder, $y$ por la eventual depreciación de la moneda nacional que la liberalización de las importaciones tendería a traer aparejada en el mercado cambiario.

La respuesta de los sustituidores de importaciones depende de la magnitud del cambio que experimenten los precios relativos, de su celeridad y de la capacidad de ajuste de los productores afectados. Lo optimo es que a los productores se les otorgue el tiempo necesario para poder efectuar la reestructuración, pero no más del estrictamente necesario, para así empujar efectivamente hacia el cambio. Por ejemplo, la redundancia ("agua") en la protección puede eliminarse abruptamente; sin embargo, la reducción de la protección efectiva debe ser graduada según la velocidad con que los productores pueden introducir innovaciones, aumentar la especialización y reasignar recursos. El ritmo del ajuste depende de la credibilidad que inspire el cronograma de cambio y del acceso que tengan los productores a los recursos necesarios para efectuar la reestructuración. Ello determina si la exposición a la competencia ha de resultar creativa o destructiva.

La respuesta de las exportaciones depende de la intensidad con que hagan uso de bienes importables y 
del tratamiento comercial a que éstos estaban afectos antes de la reforma. Con frecuencia, los insumos y bienes de capital importados por exportadores han disfrutado de ciertas franquicias arancelarias. Pero en algunos casos las exportaciones han sido desalentadas por un régimen de importaciones inoperante y arbitrario.

Un factor determinante de la respuesta de la producción, tanto de bienes exportables como importables, es la evolución del tipo de cambio real. Para que una reforma sea exitosa es preciso que el efecto neto del cambio en los incentivos involucre impulsos positivos para la producción de bienes transables en el mercado internacional. La capacidad de reestructuración dependerá también del dinamismo global de la inversión e innovación tecnológica, de la disponibilidad de mano de obra capacitada, de la funcionalidad del mercado interno de capitales, de la infrastructura $y$ del acceso a los mercados externos.

La combinación de cambios en los precios relativos, en su credibilidad y gradualidad, y en el marco macroeconómico y mesoeconómico en que se desenvuelve la reforma, define si sus efectos en la asignación de recursos son predominantemente positivos o negativos. Ello determina dos opciones: si la reestructuración parte por expandir la frontera productiva, al estilo de las economías de industrialización reciente (EIR) asiáticas, o si se inicia con una caída en la actividad económica, en un proceso de ajuste que transita bajo la frontera de producción (gráfico 1).

GRAFICO

Asta y América Latina: Hechos estillzados de dos opclones de reforma comerclal

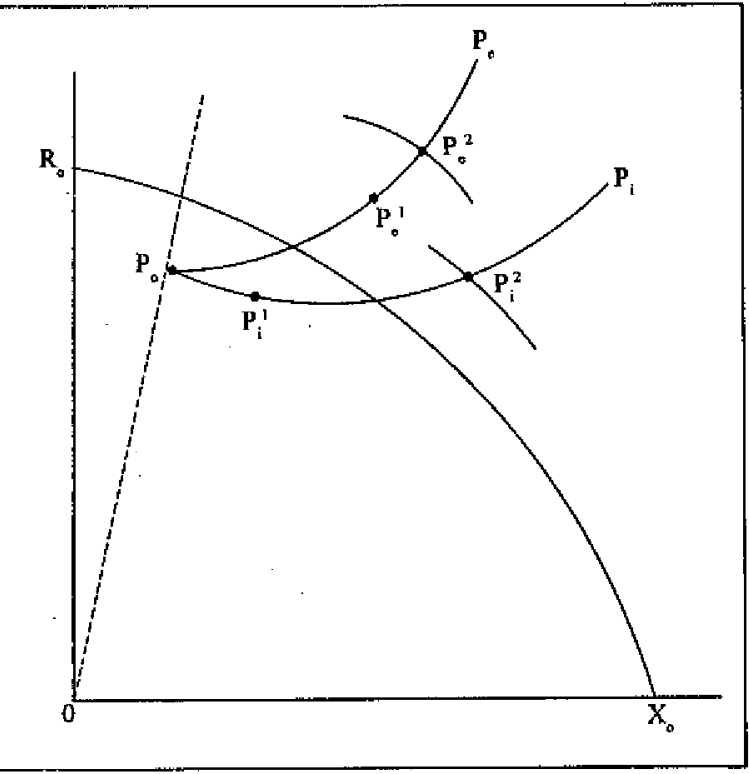

En el gráfico indicado, el eje de $X$ indica el valor agregado en la producción de exportables y $R$ (la suma de los bienes importables y de los no transables) el resto del PIB. $R_{o} X_{o}$ es la frontera inicial, y $P_{o}$ es el punto inicial de producción, situado bajo la frontera, que involucra un coeficiente de exportaciones reducido y cierta ineficiencia asignadora. La reforma debe acercar la producción efectiva a la frontera y trasladarla a una estructura con mayor participación de bienes exportables, en un marco de expansión dinámica de la frontera.

En una estrategia de internacionalización liderada por las exportaciones y sólo secundada por la liberalización de las importaciones - al estilo de las economías dinámicas asiáticas - el ajuste tenderá a seguir una trayectoria como la curva $P_{o} P_{e^{*}}$. Esta trayectoria muestra un crecimiento más que proporcional de $X$ acompañado de un aumento moderado de $R$, con una frontera productiva en expansión y una elevación gradual de la eficiencia de las empresas existentes. La economía se posiciona en o cerca de una frontera de producción que se expande sostenidamente.

La curva $P_{o} P_{i}$ muestra una estrategia alternativa -al estilo latinoamericano-, con una trayectoria liderada por la liberalización de las importaciones, con una significativa quiebra de sustituidores y un aumento paulatino de las exportaciones. Los impulsos de la "desustitucion" predominan en las etapas iniciales del proceso. Por ello la economía se posiciona por debajo de una frontera de producción que además permanece estancada en los años iniciales.

Es posible que cada una de las empresas que sobreviva en el marco de la segunda estrategia sea en promedio más fuerte y dinámica que en el primer caso. Sin embargo, durante los primeros años de ajuste los recursos productivos disponibles y en uso serán menores, debido a la mayor intensidad de quiebras y redimensionamientos: habrá una subutilización mayor de recursos, y se tenderá a estimular más débilmente la inversión total. Por lo tanto, una mayor "eficiencia microeconómica" tenderá a coexistir con una menor "eficiencia macroeconómica". La histeresis del proceso es determinante del resultado final. En efecto, lo que acontezca durante la transición afectará decisivamente el bienestar y la estructura productiva que se alcancen al final del proceso de ajuste.

Es claro que cada una de las dos opciones admite muchas variantes en el proceso de transformación productiva. Incluso al interior de cada categoría de productos tenderá a haber diferentes senderos intertemporales. Hay también cruces entre categorías: sus- 
tituidores de importaciones que se transforman total o parcialmente en importadores, o que con las reformas pasan a ser también exportadores (Katz, 1993). Sin embargo, al concentrarnos sólo en dos casos diferenciados nítidamente queremos ilustrar dos grupos de estilos contrapuestos de internacionalización. El gráfico 1 presenta las dos estrategias alternativas, mostrando la trayectoria y el destino final, representado por los puntos de producción $P_{i}^{2}$ y $P_{e}{ }^{2}$. Ambos muestran incrementos fuertes de $X$ pero muy diversos de $R$. El punto $P_{e}^{2}$ se asimila al caso de economías como las de Japón, la República de Corea y la provincia china de Taiwán, cuyo PIB ha crecido notablemente por un largo período, con una inserción externa liderada por $X$. Por su parte Brasil, se ubica en los años sesenta y setenta en una curva dinámica pero con una expansión más pareja de $X$ y $R$ (en las proximidades de la prolongación de $O P_{\partial}$ ). Chile, en cambio, está mejor representado por $P_{e}{ }^{2}$, con una fuerte expansión de $X$ pero un estancamiento de $R$ al comparar con $P_{o}$ : entre 1981 y $1989, X$ crece sustancialmente (suben $51 \%$ las exportaciones de bienes y servicios per cápita) en tanto que $R$ aumenta levemente en total y decrece por habitante (sube la producción de bienes importables y baja la de bienes no transables). Sin embargo, en la parte final del proceso, el crecimiento es vigoroso incluso en $R$ (como lo fue entre fines de los ochenta y 1993).

\section{Chile}

La liberalización comercial chilena es la más antigua en la región y la que se ha aplicado con mayor persistencia. A fines de 1973, antes de la iniciación de las reformas, el comercio exterior chileno estaba altamente intervenido: los aranceles nominales promediaban $94 \%$ y tenían una dispersión que iba del 0 al $750 \%$; el $50 \%$ de las importaciones debía ser aprobado por el Banco Central; existŕa un sinnúmero de medidas no arancelarias, tales como altos depósitos previos para el $60 \%$ de las importaciones, y había un complicado sistema de cambios múltiples, con ocho tipos de cambio oficiales y una diferencia entre el máximo y el mínimo de 1 000\% (Ffrench-Davis, Leiva y Madrid, 1991; Meller, 1992).

i) La reforma radical de los años setenta. Como parte de un amplio programa de entregar a las fuerzas del mercado la gran mayoría de las decisiones económicas, en 1973 se inició una reforma de la política comercial que comprendió la eliminación de todas las restricciones no arancelarias, la reducción de los aranceles y la unificación del tipo de cambio. Aunque esta no fue una meta inicial del programa, se liegó en junio de 1979 a un arancel parejo y bajo $(10 \%)$.

Durante los dos primeros affos de la liberalización comercial, las devaluaciones reales del tipo de cambio (que estaba oficialmente controlado) contrarrestaron la disminución de la protección nominal media (cuadro 2). Esto dio un fuerte impulso a las exportaciones distintas del cobre y otorgó cierta protección a las actividades sustituidoras de importaciones más eficientes. Pero a partir de 1976, con altibajos, el tipo de cambio real empezo a rezagarse. Por una parte, el énfasis de la política cambiaria gradualmente pas 6 del apoyo a la apertura de la economía al control de la inflación. Esto culminó en 1979, cuando se fijo el tipo de cambio nominal, con la expectativa de que la inflación interna se acercara rápidamente a la internacional.

\section{CUADRO 2}

Chlle: Arancel promedio y tipo de camblo real, 1973-1992

\begin{tabular}{lccc}
\hline Año & $\begin{array}{c}\text { Arancel promedio } \\
\text { (porcentaje) }\end{array}$ & \multicolumn{2}{c}{$\begin{array}{c}\text { Tipo de cambio real } \\
(1980=100)\end{array}$} \\
\cline { 3 - 4 } & & Total países & Sin America Latina \\
\hline 1973 & $94.0^{\circ}$ & - & $110.0^{c}$ \\
1974 & 75.6 & - & 115.2 \\
1975 & 49.3 & - & 156.2 \\
1976 & 35.6 & - & 126.6 \\
1977 & 24.3 & - & 105.6 \\
1978 & 14.8 & - & 117.2 \\
1979 & 12.1 & - & 114.6 \\
1980 & 10.1 & - & 100.0 \\
1981 & 10.1 & - & 85.0 \\
1982 & 10.1 & - & 98.7 \\
1983 & 17.9 & - & 118.5 \\
1984 & 24.4 & - & 122.0 \\
1985 & 25.8 & - & 152.2 \\
1986 & 20.1 & 171.8 & 171.8 \\
1987 & 20.0 & 179.2 & 179.0 \\
1988 & 15.1 & 191.0 & 186.1 \\
1989 & 15.1 & 186.6 & 174.9 \\
1990 & 15.1 & 193.6 & 170.4 \\
1991 & 13.1 & 182.8 & 164.2 \\
1992 & 11.1 & 168.2 & 152.0 \\
\hline
\end{tabular}

Fuente: Ffrench-Davis, Leiva y Madrid (1991) y Banco Central de Chile,

a Promedio simple, excluyendo tratamientos preferenciales como los de la Asociación Latinoamericana de Libre Comercio (ALADI) y el Acuerdo Chile-México.

'El rubro "Total paises" incluye en la construcción del f́ndice de precios externos a: Alemania, Argentina, Brasil, Canadá, Espafia, Estados Unidos, Italia, Japon, Pení, el Reino Unido y la República de Corea. El rubro "Sin America Latina" excluye Argentina, Brasil y Perú. Hasta 1985 los datos provienen de Ffrench-Davis, Leiva y Madrid (1991), y a partir de 1986 del Banco Central de Chile. Para el rubro "Total páses", por razones metodológicas, solo se presenta información a partir de 1986.

${ }^{\circ}$ Diciembre de 1973 
Por otra parte, la apreciación cambiaria fue posible por la combinación de la apertura de la cuenta de capital y la alta liquidez de los mercados internacionales financieros. Así, a partir de 1977 las limitaciones cuantitativas que tenían los bancos nacionales para endeudarse en el exterior con el propósito de hacer préstamos en moneda nacional fueron gradualmente relajadas (y eliminadas a mediados de 1979). La incidencia de los plazos mínimos de endeudamiento también se redujo, hasta que éstos se eliminaron en 1982. La gran afluencia de capitales extranjeros hacia Chile, donde las tasas de interes en moneda nacional eran considerablemente más altas que en los mercados internacionales, sustentó la apreciación real del peso (Ffrench-Davis, Leiva y Madrid, 1991).

Es interesante anotar que en 1979, al completarse la liberalización comercial y llegarse a un arancel uniforme del $10 \%$, el tipo de cambio real estaba casi al mismo nivel que a comienzos del proceso en 1974. Aunque al inicio el arancel medio nominal (94\%) contenía muchas redundancias y el exceso de los precios nacionales sobre los internacionales era indudablemente menor, lo cierto es que tal disminución de aranceles no había tenido precedentes en América Latina. La teoría elemental de la política comercial hubiera indicado la necesidad de realizar una devaluación compensatoria. De hecho, se hizo lo contrario. En los tres años que siguieron al término del programa de liberalización de las importaciones, la apreciación cambiaria se aceler $\delta$, con un fuerte impacto depresivo sobre las actividades productoras de bienes transables (Ffrench-Davis, 1986).

ii) Rectificación de la reforma en los años ochenta. La crisis interna y de balanza de pagos que sobrevino en 1982 como consecuencia de una conjunción de errores en el manejo económico y de tres severas perturbaciones (shocks) de carácter externo (la suspensión del crédito externo, el aumento de las tasas de interés y la caída de los precios del cobre) hizo descender la demanda agregada en $27 \%$ y el PIB en más de $15 \%$ entre 1981 y 1983 . Para enfrentar la crisis se procedi 6 a varias devaluaciones discretas a partir de 1982 y luego a la reinstauración de un tipo de cambio reptante. Entre 1981 y 1988 el precio real de la divisa aumentó en $119 \%$. Al mismo tiempo, el arancel fue elevado en etapas sucesivas hasta $35 \%$ en septiembre de 1984 (con promedios anuales de 24 y $26 \%$ en 1984 y 1985 , respectivamente). A medida que la aguda escasez de divisas fue menguando, hubo sucesivas rebajas del arancel, comenzando en marzo de 1985, hasta situarlo en $11 \%$ a mediados de 1991.
Después de la crisis la política comercial se flexibilizó en varios sentidos. Por una parte, se empezó a hacer uso activo de medidas antidumping y derechos compensatorios, para proteger a la economía de prácticas comerciales desleales. Para esto se elevó el arancel hasta un máximo de 35\% (nivel consolidado por Chile en el GATT en 1979) pata aquellas importaciones en las que se podía comprobar dumping o subsidios. Además, se adoptó un sistema de bandas de precios para tres productos agrícolas (trigo, azúcar y oleaginosas), lo que implicó también una desviación del arancel parejo, variable según la evolución de los precios internacionales de esos productos. En lo que se refiere a las exportaciones, los sistemas de reintegro de derechos aduaneros fueron perfeccionados y se adoptó un sistema simplificado para exportaciones menores, por el cual éstas tienen derecho a un reembolso de hasta el $10 \%$ del valor exportado cuando las exportaciones para toda la partida arancelaria correspondiente no sobrepasan un máximo anual (fijado actualmente en 20 millones de dolares).

iii) Contraste entre ambas reformas. En resumen, en Chile hubo dos reformas comerciales, una radical en el período 1974-1979 y otra moderada en 1985-1991. Si bien es cierto que las características de la política comercial, en cuanto a la prescindencia de medidas no arancelarias y el uso de un arancel parejo, no se modifico ya a partir de 1979 , el nivel del arancel había vuelto a ser relativamente elevado en 1984 y se acompaño de medidas contra la competencia desleal y de las mencionadas bandas de precios. De hecho, en 1984-1989, el arancel promedio el 20\%, duplicando el promedio registrado en 1979-1982. Pero la diferencia fundamental residio en que, durante la primera liberalización, luego de una depreciación inicial, el tipo de cambio se revaluó progresivamente. Por el contrario, en la década del ochenta, la reducción del arancel desde un máximo de $35 \%$ en septiembre de 1984 al $11 \%$ en junio de 1991 (su nivel actual) fue acompanfada de una fuerte devaluación real (asociada a la crisis de la deuda), que dio señales positivas a los exportadores y que, a la vez, mucho más que compensó el leve efecto negativo de la reducción de aranceles en la producción de bienes que compiten con las importaciones. Esto determino que durante la segunda liberalización haya habido un crecimiento más sostenido de la producción de bienes exportables. Pero, a diferencia de la primera experiencia, también hubo una significativa recuperación de la producción de sustitutos de las importaciones, principalmente entre 1984 y el final del decenio. 
Este mayor pragmatismo también se ha extendido a las políticas cambiarias y a la cuenta de capitales de la balanza de pagos. Desde 1987, Chile ha debido enfrentar una nueva afluencia de capitales externos. Mientras que en la primera liberalización comercial se permitió una prolongada apreciación cambiaria asociada a una política cada vez más liberal ante los flujos de capitales privados, a mediados de 1990 se ha intentado contener la apreciación y así proteger el dinamismo de la producción de bienes transables. Para ello, la política se ha desviado de la apertura irrestricta al ingreso de capitales y se ha tratado de dificultar el arbitraje internacional de tasas de interés. El Banco Central ahora utiliza un tipo de cambio reptante cuya paridad de referencia no es ya el dólar sino una canasta de monedas. Esta canasta determina el valor central para el dólar, el cual fluctúa dentro de una banda de $20 \%$, con una activa flotación sucia. En to que se refiere a las corrientes de capital, los créditos externos de corto plazo están sujetos a un encaje (30\% en la actualidad). Estas políticas han frenado la tendencia a la apreciación cambiaria real que comenzó a manifestarse a comienzos de 1988 y se acentuó entre enero de 1991 y fines de 1992 (Agosin, Fuentes y Letelier, 1993).

Al extraer algunas conclusiones de la experiencia chilena (Ffrench Davis, Leiva y Madrid, 1991), es indudable que la segunda reforma arrojó resultados más positivos que la primera. La primera se inició con una profunda depresión (1974-1975) y terminó con otra (1981-1982). Ambas crisis estuvieron asociadas a severas perturbaciones externas, cuyos efectos internos se acentuaron como consecuencia del dogmatismo con que se implementó la liberalización externa de la economía y de la confusión que imperó en cuanto a los objetivos y a los instrumentos de política que era necesario utilizar para lograrlos.

En la primera liberalización comercial, las fuertes rebajas arancelarias y el desmantelamiento de los controles cuantitativos habrian tenido un impacto mayor sobre el dinamismo exportador que el que tuvo la rebaja arancelaria mucho más modesta de la segunda liberalización: la reforma comercial en el primer caso partió de una situación en la que los precios internos de los bienes importables corrientes (de consumo e intermedios $)^{5}$ estaban desvinculados de los precios internacionales; por lo tanto, el "espacio" existente para reducir costos mediante la sustitución de insu-

\footnotetext{
${ }^{5}$ En general las importaciones de bienes de capital disfrutaban de
} franquicias amplias. mos nacionales por importados y las posibilidades de inducir cambios en las rentabilidades relativas eran enormes. Pero debe considerarse que, dado el marco recesivo en que se efectuaron las reformas, lo abrupto de ellas y el desempeño del tipo de cambio y de las tasas de interés, el logro exportador tuvo un costo altísimo y el dinamismo del sector exportador no se transmitió al resto de la economía: el PIB per cápita (medido entre los niveles máximos de 1974 y 1981) se expandió a menos del $1 \%$ por año, la inversión estuvo muy por debajo de sus niveles históricos y hubo un fuerte proceso de desindustrialización (cuadro 3).

A partir de 1984 la economía chilena experimentó primero una recuperación y luego un crecimiento sostenido basado en la expansión de la oferta exportable en sectores no tradicionales. Por cierto, el comportamiento dinámico de las exportaciones no tradicionales no se debió principalmente a la reducción de los aranceles, ya que la baja fue muy moderada y los exportadores cuentan con mecanismos de reintegro de derechos de aduana.

En el segundo período de liberalización, la depreciación cambiaria fue el factor más importante del éxito exportador chileno (Agosin, Fuentes y Letelier, 1993); recuérdese que el tipo de cambio real más que se duplicó entre 1981 y 1988 . Por otra parte, la participación de la inversión extranjera directa (IED) en dichas exportaciones fue fundamental. Esto sugiere que las políticas hacia la IED, que han sido muy favorables a ella y se han mantenido estables desde 1974, han contribuido más que la reducción de aranceles a incentivar el dinamismo exportador.

Dos aspectos que deben matizar la evaluación de las dos reformas comerciales chilenas se refieren a sus impactos sobre la formación de capital y sobre el dinamismo del sector industrial. Si bien la formación bruta de capital fijo y la productividad del capital han aumentado desce que se superó la crisis de comienzos de los años ochenta, el coeficiente de inversión fija todavía no sobrepasaba a comienzos de los años noventa el $20 \%$ del PIB, cifra alcanzada ya en los años sesenta. La incapacidad de la economía de superar dicho nivel de inversión impidió lograr una tasa significativa de crecimiento entre 1974 y fines de los años ochenta, periodo en el cual el crecimiento acumulado solo alcanzó un promedio de $2.3 \%$ anual.

Durante la primera liberalización comercial hubo una importante desindustrialización de la economía, la que se manifestó en una baja de cinco puntos porcentuales en la participación de las manufacturas en el PIB. Muchas empresas manufactureras potencial- 
CUADRO 3

Chlle: Indlcadores seleccionados del proceso de crecimlento, 1961-1992a

(Porcentajes)

\begin{tabular}{|c|c|c|c|c|c|}
\hline & $1961-1971$ & $1971-1974$ & $1974-1981$ & $1981-1989$ & 1989-1992 \\
\hline $\begin{array}{l}\text { Tasa de crecimiento } \\
\text { del PIB }\end{array}$ & 4.7 & 0.3 & 2.6 & 2.3 & 6.0 \\
\hline \multicolumn{6}{|c|}{$\begin{array}{l}\text { Tasa de crecimiento de las } \\
\text { exportaciones reales }{ }^{b}\end{array}$} \\
\hline Totales & 3.4 & 9.1 & 7.1 & 8.5 & 10.9 \\
\hline \multirow[t]{2}{*}{ Excluido el cobre } & 4.7 & 8.5 & 12.8 & 11.5 & 13.4 \\
\hline & $1961-1970$ & $1971-1973$ & $1974-1981$ & $1982-1989$ & $1990-1992$ \\
\hline \multicolumn{6}{|l|}{ Inversión bruta } \\
\hline fija/PIB & 20.2 & 15.9 & 15.7 & 15.2 & 19.1 \\
\hline Manufacturas/PIB & 25.4 & 27.2 & 22.0 & 20.5 & 20.6 \\
\hline Exportaciones $/ \mathrm{PIB}$ & 12.0 & 9.9 & 20.2 & 27.0 & 32.4 \\
\hline
\end{tabular}

Fuente: Cáleulo de los autores sobre la base de cifras del Banco Central de Chile y de Ffrench-Davis y Muf̃oz, 1990, cuadros 1, 3 y 6.

a precios de 1977.

${ }^{b}$ Exportaciones de bienes.

${ }^{c}$ Exportaciones de bienes y servicios.

mente fuertes quebraron a raíz de la constelación particular de políticas comerciales y cambiarias utilizadas durante ese periodo.

A pesar de los éxitos de la segunda liberalización, el proceso de desindustrialización de la primera no se ha revertido, y las exportaciones continúan concentradas en rubros que hacen uso intensivo de recursos naturales. Sin embargo, los productos con mayor valor agregado han ido captando un espacio creciente, la inversión ha seguido elevándose, y la creación de nueva capacidad productiva - aunque sólo a partir de los años noventa- ha empezado a expandirse a una tasa sostenible superior a la registrada en los años sesenta.

\section{Méxlco}

Al igual que Chile, México puso en práctica a mediados de 1985 un programa drástico de liberalización de las importaciones y de gradual desmantelamiento de los instrumentos tradicionales de política industrial. Es importante anotar que, en contraste con la experiencia chilena de los años setenta, la liberalización mexicana fue precedida y seguida de fuertes depreciaciones cambiarias reales (en 1982-1983 y en 19861987) que le dieron al sector industrial un importante colchón cambiario para realizar el ajuste (Ten Kate,
1992). Las fuertes devaluaciones fueron necesarias para enfrentar las crisis de balanza de pagos y fiscal que se produjeron a raíz de la suspensión del crédito externo (en 1982) y de la caída experimentada por el precio del petróleo (en 1986-1987). ${ }^{6}$

Antes del comienzo de la liberalización comercial, México hacía uso de una gran variedad de instrumentos para controlar las importaciones, estimular la producción industrial y orientar al sector manufacturero hacia los mercados externos. Aparte de una estructura arancelaria con alta dispersión y con una tarifa tope de $100 \%$, la producción local era protegida por permisos de importación que cubrían un $92 \%$ de las importaciones, y por la utilización de precios oficiales de aforo más altos que los precios de compra para un $19 \%$ de ellas. Los exportadores de bienes no tradicionales se beneficiaban de importantes franquicias tributarias, las que compensaban el sesgo antiexportador de la política comercial. Por último, México había utilizado exitosamente durante mucho tiempo programas de promoción industrial orientados a la

\footnotetext{
${ }^{s}$ Recuérdese que en México, al igual que en Chile, las devaluaciones contribuyen al equilibrio fiscal, ya que los ingresos provenientes del principal producto de exportación constituyen una fuente importante de recaudaciones impositivas, y transforman al sector público en un ofertante neto de divisas.
} 
sustitución de importaciones en "sectores estratégi$\cos$ " (en algunos casos en forma conjunta con la promoción de las exportaciones). Estos programas, que otorgaban protección en el mercado interno e incentivos fiscales, a cambio de lo cual las empresas debían alcanzar grados de integración local o metas de exportación cada vez más altos, se habían convertido en el principal instrumento de política industrial durante la "etapa difícil" del proceso de sustitución de importaciones (Ros, 1992).

i) La reforma iniciada en 1985 . El programa de liberalización comercial comenzó en julio de 1985 con la eliminación de los controles cuantitativos para un gran número de posiciones arancelarias. La liberalización afectó principalmente a los bienes intermedios y de capital, así como, más selectivamente, a algunos bienes de consumo. Los aranceles fueron inicialmente altos para compensar la eliminación de controles directos. En julio de 1986, México adhirió al GATT y, como "precio de entrada", se comprometió a continuar la sustitución de los controles directos por aranceles, seguida de reducciones arancelarias. Al mismo tiempo se estableció un sistema antidumping. A fines de 1987, junto con la introducción del llamado Pacto de Solidaridad Económica, se profundizó la reforma comercial: se eliminó una buena parte de los permisos previos que afectaban a las importaciones de bienes de consumo, se suprimieron los precios oficiales restantes, y se simplificó el arancel, reduciéndolo a sólo cinco tasas en un rango de 0 a $20 \%$, con un promedio ponderado por la producción de $12 \%$ ( $6 \%$ ponderado por las importaciones). Algunos ajustes posteriores para reducir aún más la dispersión del arancel aumentaron algo el promedio, pero no cambiaron en forma apreciable el enfoque liberal de la política comercial mexicana.

La reforma comercial mexicana se ha hecho extensiva a las exportaciones. Se han eliminado muchos de los permisos de exportación. Las restricciones cuantitativas a las exportaciones que aún siguen vigentes están determinadas por la existencia de controles de precios (de algunos bienes agrícolas) y por acuerdos bilaterales o internacionales (sobre el café, el azúcar, el acero y los textiles, productos que todavía representan el $24 \%$ de las exportaciones no petroleras, incluido el valor agregado de la maquila). Los instrumentos tradicionales de subsidio a las exportaciones han sido eliminados, en parte como consecuencia de acuerdos bilaterales con Estados Unidos. Los únicos incentivos a las exportaciones que se usan en la actualidad son programas que eximen de derechos a las importaciones "temporales" y de permisos de importación a los insumos de empresas exportadoras.

También ha habido una reducción significativa en el uso de políticas de promoción industrial. Los programas que restan, los cuales siguen incluyendo restricciones cuantitativas a las importaciones, se han concentrado en las industrias automotriz, de microcomputadoras y farmacéutica.

El amplio colchón cambiario creado por las devaluaciones reales de 1986 y 1987 le permitio al gobierno lanzar el Pacto de Solidaridad Económica, el cual incluía el congelamiento del tipo de cambio, la profundización de la liberalización comercial y la moderación salarial. En efecto, el tipo de cambio comenzó a ser utilizado como herramienta antinflacionaria. Durante 1988, el tipo de cambio nominal fue congelado; desde 1989, las devaluaciones nominales han sido menores que el ritmo de la inflación neta (la interna menos la externa). Desde 1987, el tipo de cambio real efectivo se ha apreciado en forma sostenida (cuadro 4).

El Programa de Solidaridad Económica tuvo gran éxito en reducir fuertemente la inflación. Junto con la privatización de la banca y el ingreso al Plan Brady, contribuyó a cambiar las expectativas con respecto al futuro de la economía mexicana. A su vez, este cambio comenzó a inducir fuertes entradas de capital extranjero y repatriaciones de capital fugado durante la crisis de la deuda externa. La afluencia de capitales extranjeros ha hecho posible sustentar la revaluación real del peso mexicano y ha promovido la intensificación del proceso revaluatorio. Los flujos de capitales extranjeros también han sido estimulados por reformas en otras áreas de política económica, como la desregulación interna, las privatizaciones masivas de empresas públicas, la apertura a la inversión extranjera y la autorización para que operen fondos mutuos extranjeros de valores bursátiles. Para moderar las entradas de capital, en abril de 1991 se restablecieron ciertos controles a las captaciones de los bancos en moneda extranjera: un porcentaje de dichas captaciones no puede prestarse en pesos y debe mantenerse en activos líquidos en divisas; además, las captaciones en divisas no pueden sobrepasar el $10 \%$ de las captaciones totales.

ii) El desempeño de las exportaciones y el producto interno bruto. México ha logrado altas tasas de crecimiento de las exportaciones de manufacturas y un leve aumento de la participación del sector industrial en el PIB. Sin embargo, las tasas de crecimiento de la economía mexicana han sido 
CUADRO 4

Méxlco: Indicadores de la política comerclal y tipo de camblo real, 1981-1992

(Porcentajes)

\begin{tabular}{|c|c|c|c|c|c|c|}
\hline Año & $\begin{array}{l}\text { Producción } \\
\text { interna } \\
\text { protegida } \\
\text { por } \\
\text { permisos de } \\
\text { importación }{ }^{\text {ab }}\end{array}$ & $\begin{array}{l}\text { Producción } \\
\text { interna } \\
\text { protegida } \\
\text { por precios } \\
\text { oficiales }^{\text {ab }}\end{array}$ & $\begin{array}{c}\text { Arancel } \\
\text { promedio }^{\mathrm{ab}}\end{array}$ & $\begin{array}{l}\text { Número de } \\
\text { tramos } \\
\text { arancelarios }\end{array}$ & $\begin{array}{l}\text { Arancel } \\
\text { máximo }\end{array}$ & $\begin{array}{c}\text { Tipo de } \\
\text { cambio real } \\
(1985=100)\end{array}$ \\
\hline 1981 & 64.0 & 13.4 & 22.8 & $\ldots$ & $\ldots$ & 72 \\
\hline 1983 & $\ldots$ & $\ldots$ & $\ldots$ & $\ldots$ & $\ldots$ & 115 \\
\hline 1984 & 92,2 & 18.7 & 23.5 & $\ldots$ & $\ldots$ & 100 \\
\hline 1985 & 47.1 & 25.4 & 28.5 & 10 & 100 & 100 \\
\hline 1986 & 39.8 & 18.7 & 24.5 & 11 & 50 & 139 \\
\hline 1987 & 25.4 & 0.6 & 11.8 & 11 & 40 & 145 \\
\hline 1988 & 21.3 & - & 10.2 & 5 & 20 & 118 \\
\hline 1989 & 19.8 & - & 12.5 & 3 & 20 & 110 \\
\hline 1190 & 17.9 & - & 12.4 & 3 & 20 & 108 \\
\hline 1991 & $\ldots$ & - & 12.0 & 3 & 20 & 98 \\
\hline 1992 & $\ldots$ & - & 12.0 & 3 & 20 & 91 \\
\hline
\end{tabular}

Fuente: Ten Kate (1992), Ros (1992), CEPAL (1992a), y CEPAL (1992b).

${ }^{a}$ Las cifras para 1985 a 1990 corresponden a diciembre de cada afio; las cifras para 1981 corresponden a abril de 1980 y las cifras para 1984 corresponden a junio de 1985 .

${ }^{\mathrm{b}}$ Ponderado por la producción.

' Tipo de cambio aplicable a las exportaciones (CEPAL, 1992a).

modestas en el período posterior a las reformas (cuadro 5). Entre 1985 y 1992 no ha habido aumento en el PIB per cápita; la inversión se ha recuperado de manera significativa, pero aún continúa a nive- les inferiores a los historicos (los coeficientes de inversión se han situado entre 16 y $22 \%$ del PIB, comparados con cifras de entre 22 y $25 \%$ en los años setenta).

CUADRO 5

México: Algunos indlcadores de crecimlento, 1980-1992

\begin{tabular}{|c|c|c|c|c|c|c|}
\hline \multirow{3}{*}{ Antos } & \multirow{3}{*}{$\begin{array}{c}\text { Tasa de } \\
\text { crecimiento } \\
\text { del PIB } \\
\text { (porcentajes) }\end{array}$} & \multirow{3}{*}{$\begin{array}{l}\text { Inversion fija/ } \\
\text { PIB } \\
\text { (porcentajes) }\end{array}$} & \multirow{3}{*}{$\begin{array}{l}\text { Manufacturas' } \\
\text { PIB } \\
\text { (porcentajes) }\end{array}$} & \multicolumn{3}{|c|}{ Exportaciones no petroleras } \\
\hline & & & & \multicolumn{2}{|c|}{$\begin{array}{l}\text { Miles de millones } \\
\text { de dólares }\end{array}$} & \multirow{2}{*}{$\begin{array}{c}\text { Como porcentaje } \\
\text { de exportaciones } \\
\text { totales }\end{array}$} \\
\hline & & & & Brenes & $\begin{array}{l}\text { Servicios de } \\
\text { maquila }\end{array}$ & \\
\hline $1970-1979$ & 6.5 & $23.4^{b}$ & 22.8 & $\ldots$ & $\ldots$ & 85.9 \\
\hline 1980 & 9.2 & 24.8 & 22.1 & 6.0 & 0.8 & 40.0 \\
\hline 1985 & 2.6 & 17.9 & 21.4 & 6.9 & 1.3 & 35.6 \\
\hline 1986 & -3.8 & 16.4 & 21.0 & 9.7 & 1.3 & 63.6 \\
\hline 1987 & 1.9 & 16.1 & 21.3 & 12.0 & 1.6 & 61.8 \\
\hline 1988 & 1.2 & 16.8 & 21.7 & 14.1 & 2.3 & 71.3 \\
\hline 1989 & 3.3 & 17.4 & 22.5 & 15.0 & 3.1 & 69.9 \\
\hline 1990 & 4.4 & 18.8 & 22.8 & 16.9 & 3.6 & 67.4 \\
\hline 1991 & 3.6 & 19.5 & 22.9 & 18.9 & $\ldots$ & $\ldots$ \\
\hline 1992 & 2.5 & 21.7 & 22.7 & 19.5 & $\ldots$ & $\ldots$ \\
\hline
\end{tabular}

Fuentes: CEPAL, 1992b y 1993; Ros, 1992.

${ }^{a}$ Participación de las exportaciones de bienes no petroleros más los servicios de maquila en el total de las exportaciones de bienes más los servicios de maquila.

${ }^{\mathrm{b}}$ Promedio simple 1970-1979 en dólares constantes de 1980. 
Un cambio estructural importante que ha tenido lugar en la economía mexicana ha sido el aumento sostenido de las exportaciones no petroleras, las que pasaron de 4800 millones de dólares en 1982, a 9700 millones en 1986 y a 18900 millones en 1991. A fines de los años ochenta, las manufacturas representaban un $85 \%$ del total de las exportaciones no petroleras.

Los defensores de la liberalización comercial sostienen que ha sido la liberalizacion de importaciones la que ha hecho posible el auge de las exportaciones no petroleras, al dar acceso a los productores de bienes exportables a insumos de calidad y precios internacionales, y al reducir la rentabilidad de producir para los mercados internos (incentivando indirectamente la reasignación de recursos hacia la exportación). Sin embargo, el fuerte aumento de las exportaciones no petroleras había comenzado en 1983, antes de que se diera inicio a las reformas comerciales y, por lo tanto, es difícil atribuirselo solamente a ellas. Ros (1992) ha calculado que casi la mitad del aumento de las exportaciones no petroleras en el período 1982-1988 provino de tres sectores (la industria automotriz, la de computadores y las de maquila) ${ }^{7}$ que no se beneficiaron de la apertura, ya sea porque sus importaciones de insumos ya estaban liberadas de aranceles (las maquiladoras) o porque las importaciones competitivas con sus productos o sus insumos importados continuaron siendo restringidas por programas de desarrollo industrial (los automóviles y los computadores personales).

Una hipótesis que cuadra mejor con la evolución de la economía mexicana es que el auge de las exportaciones no petroleras tuvo más que ver con las fuertes depreciaciones cambiarias reales de 1982-1983 y 1986-1987 y con la depresión de los mercados internos, que obligó a los productores a salir a buscar mercados afuera, especialmente en Estados Unidos. La mayoría de las nuevas exportaciones mexicanas de manufacturas proviene de industrias establecidas durante el período de sustitución de importaciones, con una inversión nueva relativamente modesta; no ha habido una reasignacion masiva de recursos hacia sectores en los que podría suponerse que México tiene ventajas comparativas (los que hacen uso intensivo de mano de obra y están orientados preferentemente a los mercados externos). Por lo tanto, el éxito de

\footnotetext{
${ }^{7}$ S6lo el valor agregado por el sector de maquiladoras se considera como exportación en las estadísticas mexicanas. Siguiendo a Ros (1992), aquí se reclasifican los servicios de maquila en las exportaciones de bienes.
}

México en expandir sus exportaciones le debe mucho al proceso previo de sustitución de importaciones y a los programas de desarrollo en sectores estratégicos (Ros, 1992).

\section{Bolivla}

Como parte de su programa de estabilización y ordenamiento de la economía para superar la hiperinflación y restablecer el crecimiento, en el último trimestre de 1985 Bolivia también puso en práctica un ambicioso programa de liberalizacion comercial que se ha mantenido hasta hoy (Morales, 1992). Antes del comienzo del programa de apertura, el arancel exhibía una gran dispersión, con una tarifa máxima de $150 \%$; también existran prohibiciones y requisitos de licencias para importar. Se comenzó con la unificación del tipo de cambio, el retorno a la total convertibilidad, el desmantelamiento de las restricciones cuantitativas y la reducción de los aranceles. Además, se abrío la cuenta de capitales casi totalmente. Desde entonces, ha habido devaluaciones importantes del tipo de cambio real efectivo (cuadro 1$)^{8}$

En julio de 1986 el sistema arancelario de Bolivia tuvo una significativa simplificación, estableciéndose un arancel uniforme de $20 \%$. A comienzos de 1988 el arancel para los bienes de capital se redujo a $10 \%$, manteniéndose en $20 \%$ para el resto de los bienes, nivel que hacia fines de ese mismo año bajó a 17\%. En 1990, el arancel para los bienes de capital descendio a $5 \%$ y para el resto de los bienes a $10 \%$, modalidad que se ha mantenido hasta la fecha. La economía boliviana se ha transformado en una de las más abiertas de América Latina y del mundo.

Con el fin de estimular las exportaciones no tradicionales, se instituy 6 un subsidio de $10 \%$ del valor de las exportaciones. Este instrumento, denominado Certificado de Reintegro Arancelario (CRA), tenía por objetivo reducir el sesgo antiexportador proveniente de los derechos sobre insumos importados incorporados en las exportaciones. Por razones fiscales y por acuerdo con el Fondo Monetario Internacional y el Banco Mundial, el CRA fue eliminado a principios de 1991.

Como puede apreciarse en el cuadro 6, desde que se superó la hiperinflación en 1986 las tasas de crecimiento de la economia boliviana han sido modestas, especialmente cuando se las compara con las registradas

\footnotetext{
${ }^{8}$ Bolivia utiliza un tipo de cambio flotante con intervención off-
} cial. 
en los años setenta. Luego de caídas fuertes en 1985 y 1986, en los sexenios siguientes hubo un leve aumento del PIB por habitante, de menos de $1 \%$ anual. El crecimiento económico que ha tenido lugar no ha sido suficiente para que el producto per cápita llegue al $80 \%$ del nivel prevaleciente antes de la crisis de comienzos de los años ochenta. La inversión como proporción del producto cayó después de las reformas. Particularmente inquietante es la baja en la inversion bruta fija privada desde el $7 \%$ del PIB en 1982 a menos del $4 \%$ en 1990 (Morales, 1992), con cierta recuperación en 1991-1992. Junto a la reducción drástica de la inflación, un cambio positivo ha sido la diversiftcación de las exportaciones, las cuales, empero, siguen siendo de productos minerales 0 agrícolas. Las exportaciones no tradicionales crecieron fuertemente entre 1988 y 1990, para luego decaer parcialmente en 1991 y 1992. Las exportaciones totales, por su parte, s6́lo en 1990 recuperaron un nivel similar al de 1980, para también declinar en el bienio siguiente. La experiencia boliviana demuestra que en una economía poco diversificada y con bajos niveles de productividad, una reforma en las señales del mercado para alinear los precios nacionales con los internacionales es claramente insuficiente para alentar un proceso de transformación estructural que se inicie y desarrolle oportunamente.

Cuapro 6

Bolivia: Algunos indicadores de crecimiento, 1970-1992

(Porcentajes)

\begin{tabular}{cccccc}
\hline Año & $\begin{array}{c}\text { Tasa de } \\
\text { crecimiento } \\
\text { del PIB }\end{array}$ & $\begin{array}{c}\text { Inversión bruta } \\
\text { fija / PIB }\end{array}$ & $\begin{array}{c}\text { Tasa de } \\
\text { crecimiento } \\
\text { de las } \\
\text { exportaciones } \\
\text { reales }\end{array}$ & $\begin{array}{c}\text { Exportaciones } \\
\text { totales } \\
\text { (millones de } \\
\text { dolares) }\end{array}$ & $\begin{array}{c}\text { Exportaciones no } \\
\text { tradicionales }^{\mathrm{a}} \\
\text { (millones de }^{\text {dólares) }}\end{array}$ \\
\hline $1970-80$ & 3.9 & -10.5 & & \\
$1980-84$ & -1.9 & 12.1 & -28.3 & $871^{\mathrm{b}}$ & 68 \\
1985 & -1.0 & 12.3 & -7.6 & 673 & 35 \\
1986 & -2.5 & 13.3 & 4.5 & 638 & 108 \\
1987 & 2.6 & 13.6 & -0.2 & 569 & 106 \\
1988 & 3.0 & 13.6 & 3.7 & 600 & 108 \\
1989 & 2.8 & 12.7 & 18.5 & 927 & 204 \\
1990 & 2.6 & 12.1 & 20.8 & 849 & 292 \\
1991 & 4.1 & 12.9 & 2.3 & 710 & 252 \\
1992 & 3.4 & 13.3 & -11.1 & & 205 \\
\hline
\end{tabular}

Fuente: CEPAL (1992b) y CEPAL (1993).

a Exportaciones totales excluyendo zinc, estaño, plata, wolframio, antimonio, oro, plomo, otros minerales, gas natural y otros hidrocarburos.

b Promedio simple.

\section{III}

\section{Las lecciones de las economías}

\section{dinámicas de Asia}

A pesar de su gran diversidad, las economías exportadoras de manufacturas de Asia tienen algunas características comunes en lo que respecta a sus estrategias y políticas de desarrollo (y a los resultados obtenidos), que las hacen de particular interés en una comparación con América Latina. En esta sección el análisis se basa en la experiencia de la República de Corea y de la provincia china de Taiwán, economías que se han industrializado hacia afuera por varias décadas. Desde fines de los años setenta, otras economías asiáticas (Indonesia, Malasia y Tailandia) han aplicado políticas más o menos similares, también 
con resultados favorables con respecto al crecimiento basado en las exportaciones de manufacturas (Agosin, 1992; Noland, 1990; Ariff y Hill, 1989). Todas ellas comenzaron su proceso de industrialización con un modelo de sustitución de importaciones y, sin excepción, las nuevas políticas con que buscaron orientar la economía hacia afuera fueron superimpuestas al régimen de sustitución de importaciones imperante (Noland, 1990, capítulos 2 y 3). Estas economías transitaron hacia un modelo de industrialización orientado al exterior sin saltos mortales y basándose en buena medida en el desarrollo ya alcanzado de destrezas y capacidades industriales.

En general, la estrategia que siguieron fue la de otorgar incentivos relativamente parejos a las exportaciones y a la producción para el mercado interno dentro de una misma industria, pero ofrecer incentivos bastantes distintos (y cambiantes en el tiempo) para industrias diferentes. En términos formales, el tipo de cambio efectivo, que incorpora el efecto de todos los incentivos (aranceles, subsidios, etc.) para las exportaciones era, en líneas generales, igual al tipo de cambio efectivo para los sustituidores de importaciones en una industria $i$, pero difería bastante entre la industria $\mathrm{i}$ y la industria $\mathrm{j}$ :

$$
\begin{gathered}
T C E\left(X_{i}\right) \approx T C E\left(M_{i}\right)_{i} \\
T C E_{i} \neq T C E_{j}
\end{gathered}
$$

Aunque la protección en la República de Corea y en la provincia china de Taiwán ha disminuido bastante en los últimos decenios y ahora se acerca a las prevalecientes en los países desarrollados (Noland, 1990), estas economías comenzaron su proceso de industrialización hacia afuera con niveles de protección altos, los que no fueron desmantelados en aras de la reorientación hacia la exportación. ${ }^{9}$ Lo que sí salta a la vista en el caso de las economías dinámicas de Asia es la capacidad del Estado de dar y quitar incentivos, evitando que éstos se transformen en derechos adquiridos por los grupos empresariales a los que favorecen. Llama la atención la flexibilidad con que el Estado ha podido aplicar politicas temporales de promoción. Además, todos los incentivos otorgados

\footnotetext{
${ }^{9}$ Por ejemplo, en 1976, más de un decenio después de su despegue, la República de Corea tenía aranceles que iban de 0 a $150 \%$ y para cerca de mil partidas, aproximadamente $40 \%$ del universo, las tasas eran de entre 30 y $60 \%$. Además, utilizaba profusamente mecanismos pararancelarios y exenciones (Ffrench-Davis, 1986).
}

lo fueron habitualmente a cambio del cumplimiento de metas específicas, por lo general en el campo de las exportaciones.

Una característica muy importante de estas experiencias es que las autoridades pudieron impedir que se generara una revaluacion importante del tipo de cambio o que éste sufriera grandes fluctuaciones reales, como las que han solido observarse en los países latinoamericanos. La presencia de aranceles y otras barreras comerciales de cierta importancia indica que, obviamente, las monedas de esas economías asiáticas estaban sobrevaluadas, pero el grado de sobrevaluación fue moderado y tendió a ser compensado con subsidios de diverso tipo a las exportaciones. Para poder controlar el tipo de cambio en forma eficaz, la mayoría de ellas ha ejercido un control efectivo sobre las corrientes de capitales extranjeros y ha alcanzado un grado aceptable de estabilidad macroeconómica.

La experiencia de los países asiáticos sugiere que la liberalización comercial no es necesaria para la industrializacion basada en las exportaciones. En efecto, se observa en general que las economías estudiadas pudieron mantener políticas relativamente proteccionistas y crecer hacia afuera al mismo tiempo. Dos hechos son fundamentales para explicar lo que aparece como un contrasentido desde el punto de vista de las recomendaciones convencionales de política comercial. Uno es que, en todos los casos exitosos, ha habido un uso activo de subsidios a la exportación de diversos tipos, que han servido para contrarrestar el sesgo antiexportador implícito en la protección de rubros importables; las economías asiáticas examinadas, sin excepción, cuentan con mecanismos de reintegro de aranceles y de impuestos indirectos para los exportadores, y en algunos casos, existe más de un mecanismo, pudiendo el exportador escoger de acuerdo a su situación particular. El otro es que los incentivos se han dado a cambio de desempeños específicos y por períodos limitados.

A pesar de que hay características que son comunes a todas las economías dinámicas de Asia, se observan diferencias importantes entre ellas que son interesantes de consignar, porque cada experiencia nacional contiene lecciones relevantes para América Latina. Quizás el rasgo más interesantes de la experiencia coreana ha sido el trato distinto otorgado a las industrias maduras y a las industrias nacientes (Westphal, 1992). Para las primeras, la política comercial procuró conceder un trato neutral. Vale decir, se instauraron mecanismos de reintegro de derechos 
de aduana e impuestos indirectos para los exportadores directos e indirectos (productores que venden insumos a los exportadores). En la década de 1960, estas empresas también disfrutaron de incentivos adicionales, como el acceso al crédito a tasas preferenciales, el acceso privilegiado a licencias de importación, y ciertas reducciones en los impuestos directos. ${ }^{10}$

Para las industrias nacientes promovidas por el Estado, la concesión de incentivos, aparejados a metas de exportación, fue mucho más agresiva. El método fundamental fue la creación de monopolios temporales para ciertas empresas en los ramos industriales promovidos, a cambio de metas de exportación específicas. Esto implicaba que, en la práctica, el fomento de la sustitución de las importaciones se transformaba en un mecanismo para promover las exportaciones. A corto andar, las empresas promovidas se volvieron exportadoras, subsidiando sus ventas al exterior con los fuertes beneficios obtenidos en el mercado nacional. Quizás lo determinante de este resultado fue que el sistema de incentivos que operó impulsó a las empresas beneficiadas a lograr la competitividad internacional desde el principio. Este énfasis permitió aprovechar rápidamente las economías de escala y el aprendizaje por la práctica.

Otro elemento importante fue el acceso preferente que tuvieron las empresas de los sectores beneficiados al crédito de corto y largo plazo a tasas preferenciales. En realidad, al favorecer a ciertos sectores se estaba favoreciendo a conglomerados específicos, la creación de los cuales fue impulsada por el Estado. El estímulo al surgimiento de agentes productivos en sectores promovidos por el Estado, conjuntamente con el acceso abundante al crédito a tasas de interés subsidiadas para las actividades favorecidas, fueron las formas como el Estado intentó, exitosamente, superar las insuficiencias de los mercados de capital (Amsden, 1993). La política industrial fue secuencial: en los años sesenta se privilegio la inversión en cemento, fertilizantes y refinerías de petróleo; a fines de los sesenta y comienzos de los setenta, en acero y productos petroquímicos; en los años setenta, en astilleros, bienes de capital y bienes de consumo durables (incluidos los automóviles), y en los ochenta, en eléctronica, telecomunicaciones e informática.

En la economía taiwanesa, las políticas industriales y comerciales fueron similares en ciertos sentidos, y particularmente en el carácter secuencial del apoyo del Estado a empresas y sectores específicos: ese apoyo se dio a los textiles, el vidrio, los plásticos, el cemento y los productos electrónicos de consumo en los affos cincuenta; a los textiles sintéticos y el acero en los sesenta; a los automóviles en los setenta, $\mathrm{y}$ a la industria de la información desde fines de los setenta (Wade, 1990a y 1990b, cap. 4), Como en la República de Corea, el liderazgo del Estado en la estrategia industrial se concentro en actividades con altos costos fijos y con uso intensivo de capital o en otras en las cuales la tecnología estaba monopolizada por un número reducido de oferentes potenciales. Se trataba de industrias de las cuales se esperaba que llegaran a ser competitivas internacionalmente.

Algunos de los mecanismos de promoción fueron similares a los utilizados por la República de Corea: protección del mercado local, créditos de largo plazo subsidiados y exoneraciones impositivas. Pero un aspecto algo distinto de la experiencia taiwanesa fue el uso agresivo de la empresa e inversión estatales y la promoción de la inversión extranjera (generalmente en asociación con el capital nacional) en sectores favorecidos.

Con el correr del tiempo, el liderazgo del Estado en la estrategia industrial ha ido disminuyendo y adquiriendo formas menos intervencionistas tanto en la economía taiwanesa como en la coreana. Se espera que las reformas comerciales en curso lleven a ambas a asemejarse bastante a las de los países industrializados en lo que se refiere a los niveles y dispersión de los aranceles (Noland, 1990, pp. 9-11). A medida que el Estado se retira de su papel de liderazgo en la industria, la protección en estas economías va adquiriendo la función que se le atribuye en los países industrializados: defender a los sectores más rezagados (en particular la agricultura).

\footnotetext{
${ }^{10}$ Los incentivos adicionales a los reintegros tendieron a desaparecer a partir de los años setenta. Peto tamblén fueron disminuyendo
}

los niveles de protección del mercado interno de que disfrutaban estos sectores. 


\section{IV}

\section{Elementos para}

\section{una evaluación}

El examen de las liberalizaciones latinoamericanas y de las experiencias asiáticas de más largo alcance arroja conclusiones importantes para el manejo de la política económica en América Latina. Ellas pueden ayudar a orientar las reformas en marcha, de manera que contribuyan más eficientemente a acelerar el crecimiento y a apoyar la transformación productiva. No se trata de que los países que han puesto en práctica reformas profundas desanden el camino ya recorrido. La reversión de las políticas ya adoptadas puede, en sí, tener un costo muy alto que haga conveniente la mantención de las políticas existentes, aunque ellas sean subótimas. Lo que sí es esencial es evaluar lo hecho y los resultados ya cosechados o probables, con la intención de dilucidar lo que queda por hacer para aumentar la probabilidad de que los países de la región alcancen los objetivos perseguidos con la liberalización comercial, vale decir, una inserción internacional más dinamizadora del desarrollo.

\section{La relación entre la Ilberalización de las im- portaciones y la promoción de las exporta- clones}

La experiencia demuestra que es más efectivo liberalizar las importaciones después de haber alcanzado un crecimiento sostenido de las exportaciones y una transformación dinámica del aparato productivo. Los casos del este asiático así lo atestiguan (Sachs, 1987). Es la opción 1 del esquema analítico presentado más atrás (sección II, apartado 1 y gráfico 1). Aunque este camino ya no es una opción factible para muchos países latinoamericanos, las experiencias asiáticas enseffan que es menester apuntar directamente al dinamismo exportador $y$ no esperar que la liberalizacion de importaciones, por sí sola, surta los efectos deseados sobre las exportaciones.

En la mayoría de las liberalizaciones que se están llevando a cabo en América Latina (especialmen- te en Argentina, Colombia, Perú y Venezuela), la opción de fomentar las exportaciones primero y liberalizar las importaciones después ya fue explícitamente descartada: la liberalización ya ocurrí y se hizo en un contexto en el cual la creación de capacidad productiva en las economías nacionales distaba mucho de exhibir un comportamiento dinámico, Un camino similar fue elegido por Chile, Bolivia y México, países que liberalizaron sus importaciones sin dar otro apoyo significativo a las exportaciones que la depreciación cambiaria (la cual tendió a revertirse en Chile durante el período 1979-1982 y en México a partir de 1988). Es más, en todos los países que han emprendido reformas profundas se ha procedido a desmantelar o a reducir los esquemas de promoción de exportaciones que han sido exitosos en el pasado. Esto hace pensar que los costos de las liberalizaciones, en términos de crecimiento, serán altos en la transición hacia un nuevo equilibrio. Como interrogante constructiva, cabe preguntarse, dadas las restricciones que impone el camino escogido, cómo mejorar la eficiencia global de las reformas. Las sugerencias que se hacen a continuación obedecen a este objetivo.

\section{Selectlvidad o neutralldad de 108 Incentivos}

Las principales experiencias históricas y los casos que aquí se han examinado no avalan la hipotesis de que, una vez conseguida la neutralidad de los incentivos a través del desmantelamiento de toda protección y la prescindencia de los subsidios, los recursos se reasignan espontáneamente y a bajo costo hacia los sectores en los que el país tiene ventajas comparativas. La experiencia chilena muestra los altos costos de la liberalización drástica y del abandono de toda selectividad. Esos costos (esencialmente de transición) son difícilmente compensados por el eventual mayor crecimiento que se alcance después de terminado el ajuste. Políticas más selectivas y menos drásticas en lo que respecta a la liberalización de las importaciones y un apoyo más decidido 
a las exportaciones no tradicionales, por lo que sugieren las experiencias asiáticas, habrían resultado en un comportamiento más dinámico de la economía en su conjunto.

Si se quiere llevar a cabo una transformación productiva eficiente, que incluya una mayor apertura y una inserción cualitativamente distinta en los mercados internacionales, no basta con el impulso puramente negativo de la liberalización; también serán necesarias políticas que impliquen impulsos positivos. Esto no significa, obviamente, un retorno a la protección alta e indiscriminada del pasado. En efecto, se puede argumentar que las políticas de sustitución de importaciones adolecieron del defecto de ser más bien indiscriminadas que selectivas. Lo que se requiere es una mucho mayor selectividad, no en el sentido de dar apoyos a actividades especificas (las que pueden resultar difíciles de identificar) sino de lograr que las desviaciones de la neutralidad sean pocas y bien elegidas.

Además, la selectividad deberá evitar el sesgo antiexportador de las políticas del pasado; vale decir, se deberá dar incentivos equivalentes tanto para exportar como para producir con miras a los mercados nacionales. En efecto, en las condiciones actuales y dado el tamaño pequeño de la mayoría de las economías de la region, se puede argumentar a favor de políticas francamente proexportadoras. Ya que los países latinoamericanos han optado por un arancel mayor que cero y, en todos los casos (salvo el de Chile), con algún grado de diferenciación, se hace necesario utilizar subsidios de exportación más o menos equivalentes.

En lo que se refiere al arancel, no hay razones teóricas o prácticas convincentes para optar por la absoluta uniformidad. Si la mayoría de las actividades industriales están sujetas a conomías de escala dinámicas más o menos difusas, se puede argumentar (como lo hace Rodrik, 1992) que es conveniente favorecer a grandes categorías de actividades manufactureras, sin entrar en el juego de "escoger ganadores", favoreciendo a industrias específicas. La moderación en el nivel de los aranceles y en el número de tramos ayudará a evitar abusos. Además, todo arancel por encima del nivel básico deberá ser temporario.

Como ya se ha anotado, los subsidios a las exportaciones resultan necesarios, especialmente si se quiere fomentar una industrializacion eficiente en presencia de aranceles de importacion. Un elemento indispensable para evitar el sesgo antiexportador son los sistemas de reintegros de derechos para los insumos utilizados en la producción de bienes exportables. Por otro lado, existe una larga y positiva experiencia tanto en América Latina (por ejemplo, en Colombia, Costa Rica y Brasil) como en Asia con los subsidios a las exportaciones no tradicionales. Para minimizar la posibilidad de que estos subsidios se presten a abusos, se podría pensar en un sistema de subsidios que vayan decreciendo a medida que las exportaciones aumenten, con un cronograma anunciado de antemano y no sujeto a renegociaciones.

La selectividad tiene diversos aspectos que rebasan la política comercial y que no es posible abordar con detalle aquí. Estos aspectos incluyen medidas para dar a los exportadores acceso al crédito comercial de preembarque y posembarque a tasas de interés internacionales, medidas para completar el mercado de capitales y eliminar su sesgo en contra de los proyectos nuevos, mejoramiento de la infraestructura física y social indispensable para impulsar el desarrollo exportador, políticas ante la inversión extranjera directa que favorezcan la adquisición de tecnologías nuevas y el acceso a los mercados internacionales, y la adopción de una política congruente de negociaciones comerciales internacionales para obtener acceso a los mercados internacionales donde se desea tomar posición.

Volviendo al tema de los incentivos, al formular políticas comerciales en los antos noventa tambien hay que tener en cuenta que el contexto internacional ha cambiado significativamente desde que las economías dinámicas del este asiático comenzaron sus procesos de industrialización basados en las exportaciones, en los años sesenta y setenta. Hoy es mucho más difícil recurrir a incentivos de la magnitud de los otorgados entonces por esas economías, tanto por el clima de menor dinamismo mundial y más proteccionismo que se vive en la actualidad (por lo cual ahora es más probable, por ejemplo, que los países importadores se protejan de los subsidios a la exportación con gravámenes compensatorios) como porque la reglamentación internacional en materia de política comercial se ha hecho mucho más estricta que antes. De concluir exitosamente la Ronda Uruguay, es muy probable que el campo de maniobra de los países en desarrollo para imponer subsidios a las exportaciones se vea aún más disminuido.

\section{3. ¿Apertura gradual o ráplda?}

Está claro que los países latinoamericanos que han emprendido liberalizaciones comerciales en años re- 
cientes lo han hecho en forma rápida. Por lo tanto, los comentarios que se hacen en esta sección están dirigidos más que nada a los países que aún no han consolidado sus procesos de reforma. Todavía es muy pronto para evaluar los resultados de las reformas abruptas emprendidas recientemente. Sin embargo, las experiencias asiáticas, así como las de Colombia desde la mitad de los años sesenta hasta 1989 (Ocampo y Villar, 1992) y de Costa Rica desde 1983 hasta 1990 (Herrera, 1992), parecerían recomendar un enfoque gradual que permita la reconversión de las industrias existentes en lugar de llevar a la destrucción de una proporción alta de la capacidad instalada, consecuencia inevitable de una liberalización rápida.

En Colombia, el tránsito a mediados de los años sesenta desde un modelo de sustitución de importaciones a uno mixto que daba prioridad tanto a la sustitución de importaciones como a la promoción de exportaciones, fue determinante en orientar cada vez más al sector manufacturero hacia afuera, evitando los traumas asociados con liberalizaciones drásticas como la chilena. En Costa Rica, la reducción de aranceles fue gradual y estuvo acompañada de incentivos a la exportación y de mecanismos de reintegro de derechos de aduana. La expansion de las exportaciones no tradicionales -el rasgo más significativo del desarrollo costarricence en los años ochenta- descansó en forma importante en las empresas que se hab́an establecido durante el régimen anterior de sustitución de importaciones. A ello se agreg6 la promoción deliberada de la inversión extranjera en la producción de bienes exportables textiles y electrónicos.

Ciertamente que la adopción de un enfoque gradual no significa que toda la reforma deba ser gradual. Por ejemplo, la eliminacion de redundancias en el arancel, así como la conversión de las restricciones cuantitativas en aranceles ("arancelización") y los ajustes cambiarios requeridos pueden hacerse de una vez. Pero las reducciones arancelarias posteriores deben graduarse según la capacidad de los productores de ir adaptando sus estructuras productivas a un mayor grado de competencia.

\section{El papel del tipo de camblo}

Es indudable que el manejo del tipo de cambio es un factor determinante de los resultados que se logren. Evitar el rezago cambiario parecería ser una condición indispensable para el éxito de cualquier reforma comercial, ya se trate de una liberalización drástica o de una apertura gradual y controlada. De nuevo, la experiencia chilena en el período 1976-1981 (así como la de otros países del Cono Sur en los años setenta) demuestra lo nocivo que puede ser el doble impacto de la apreciación del tipo de cambio real y de la liberalización drástica de las importaciones, en conjunto. A modo de ejemplo contrario, el nuevo ajuste realizado en Chile entre 1983 y 1991 fue más exitoso y sostenible que el practicado en los años setenta, porque la rebaja arancelaria fue complementada con una fuerte devaluación real.

La mayoría de las liberalizaciones más recientes en América Latina están ocurriendo en un contexto de fuerte apreciación cambiaria real. En efecto, algunos de los países donde la liberalización de importaciones ha sido más profunda también han experimentado pronunciados rezagos cambiarios. El manejo del tipo de cambio para apoyar la transformación del aparato productivo es un tema de política económica que todavía no ha sido asumido adecuadamente en América Latina.

La experiencia de los países latinoamericanos demuestra que la política cambiaria en sí misma no sirve como sustituto para una política antinflacionaria efectiva. Excepto en el corto plazo y con el fin de cambiar las expectativas, el ancla cambiaria para los precios internos ha demostrado ser muy endeble, particulamente en los países de más alta inflación. La estabilización del nivel de precios es indudablemente esencial para cualquier política que busque cambiar en forma permanente los precios relativos. Pero ésta no puede alcanzarse sólo fijando el tipo de cambio nominal. El tipo de cambio es una herramienta indispensable para la transformación productiva con equilibrio externo. Este es uno de los mensajes de las experiencias exitosas del este asiático.

\section{La liberallzación financiera externa}

Otra lección de las experiencias contrastantes de América Latina y Asia es que la liberalización de las corrientes internacionales de capital puede ser peligrosa para el logro de los objetivos de la apertura comercial. ${ }^{11} \mathrm{La}$ liberalización financiera tiene dos componentes que usualmente van juntos, uno interno y otro externo. La liberalización financiera interna se traduce, entre otras cosas, en dejar las tasas de interés

\footnotetext{
"Sobre el tema de la secuencia de las liberalizaciones del comercio y de la cuenta de capitales, véase Edwards, 1989. Sobre estabilidad y movimientos de capitales, véase Draz-Alejandro (1985) y Williamson (1992).
} 
a las fuerzas del mercado. Por su parte, la liberalización financiera externa se expresa en una combinación de medidas: permitir que los no residentes operen en el mercado financiero nacional o que los residentes contraten préstamos en los mercados financieros internacionales; permitir que los residentes adquieran divisas en el mercado interno para invertir o gastar en el extranjero; y permitir transacciones en moneda extranjera en los mercados internos. En tanto que la liberalización financiera interna fortalece el vínculo entre la inflación y las tasas de interés, la liberalización financiera externa debilita el vínculo entre los precios internos y el tipo de cambio (Akyüz, 1993). Esto hace más difícil poner en práctica una liberalización comercial exitosa, por dos motivos. En primer lugar, la combinación de la liberalización financiera interna con la externa hace el tipo de cambio más difícil de controlar. Segundo, ella eleva y hace más inestables las tasas de interés, desincentivando así la inversión productiva.

La liberalización simultánea de las transacciones financieras internas y externas entraña problemas serios para el manejo de la política económica. La liberalización interna generalmente conduce a fuertes alzas en las tasas de interés (tanto nominales como reales) y a grandes altibajos por un lapso prolongado; cuando llegan a existir diferencias entre las tasas de interés internas y las tasas prevalecientes en los mercados internacionales, y no se espera que esas diferencias sean igualadas por una depreciación cambiaria, los flujos de capital desestabilizadores pueden ser cuantiosos.

La liberalización financiera externa, en situaciones como las vigentes en la segunda mitad de los años setenta o al inicio de los noventa, dificulta el manejo del tipo de cambio real (Williamson, 1992). Los flujos de capital de corto plazo, que buscan ganancias especulativas en torno a las diferencias internacionales entre las tasas de interés, pueden tornar muy inestable el tipo de cambio real y dificultar el manejo de este instrumento de política económica tan crucial para la transformación productiva.

Además, la inestabilidad cambiaria y de las tasas de interés tiende a estimular el "rentismo" por sobre el "productivismo" y a entregar señales confusas a los asignadores de recursos.

En la región hay algunos ejemplos recientes de manejo relativamente exitoso de los capitales especulativos. El primero es el de Chile, país que vivió una especie de aprendizaje. En Chile, la fuerte apreciación cambiaria de fines de los años setenta se debió al acceso itrestricto que tuvieron los bancos nacionales al crédito externo. En años más recientes, una actitud más pragmática ha permitido proteger parcialmente el tipo de cambio y ha contribuido a materializar los beneficios de la liberalización comercial. Colombia también ha echado mano a un abanico de medidas para detener las entradas de capital de corto plazo que amenazaban con una mayor revaluación del tipo de cambio. Brasil y México han efectuado algunos intentos para suavizar los flujos financieros de corto plazo.

En varios otros países de América Latina, las liberalizaciones comerciales recientes han ido acompafiadas de liberalizaciones financieras más o menos acentuadas y de grandes afluencias de capital que han tendido a sobrepasar las posibilidades de "esterilización" de las autoridades monetarias. En estos países, el desmantelamiento de los controles de capital y la incapacidad de las autoridades para regularlos constituye un obstáculo para una apertura comercial exitosa en el ámbito productivo.

Entonces, en lo que se refiere a la cuenta de capitales de la balanza de pagos, el problema que se les presenta a los países de la región es el de cómo vincular a los mercados nacionales de capitales con los externos, de manera que minimice la ineficiencia artificial (apreciaciones cambiarias desequilibradoras) y los impactos desestabilizadores de los flujos de capital de corto plazo, los cuales suelen llegar cuando no se los necesita e irse cuando son esenciales para el equilibrio de la balanza de pagos. Parece indispensable, por lo tanto, distinguir entre corrientes de capital extranjero con objetivos productivos de largo plazo (por ejemplo, la inversión extranjera directa), que son beneficiosas, de otras corrientes puramente especulativas y de corto plazo, las que es esencial desestimular. 


\section{Consideraciones finales}

A modo de conclusión, puede decirse que la experiencia pareciera demostrar que, junto con racionalizar los incentivos comerciales, hay que aplicar algún grado de selectividad en la política de desarrollo productivo. Es lo que se ha hecho en los países más dinámicos del este asiático. El problema radica en encontrar los mecanismos más eficientes, entre los cuales están los incentivos decrecientes atados a metas específicas de exportación, y la necesaria reforma en la institucionalidad pública. En realidad, la selectividad debe ser mayor que en el período de sustitución de importaciones y los criterios para administrar esa selectividad deben ser claros. La protección a la producción nacional y los incentivos a las exportaciones forman parte de un conjunto de políticas con las cuales se busca llevar a cabo una estrategia de desarrollo y transformación productiva. Pero la experiencia enseña que los incentivos deben ser moderados y con límites definidos en el tiempo; que las desviaciones con respecto a la neutralidad deben ser pocas y escogidas cuidadosamente, y que es indispensable compensar el sesgo antiexportador de la protección con incentivos para exportar. También parece más eficiente otorgar incentivos por grandes categorías de actividad - las que tengan mayores posibilidades de ofrecer beneficios dinámicos no internalizados por el mercado- en lugar de tratar de escoger ganadores específicos. La promoción de las exportaciones no tradicionales surge como un campo particularmente apropiado para las políticas comerciales selectivas.

Otros aspectos de la selectividad mencionados en este trabajo y que han sido desestimados en las reformas recientes (o de más larga data, como en el caso de Chile) se refieren a lo que haga el Estado para corregir las fallas del mercado que dificultan la inversión orientada a la transformación productiva. Esa acción incluye políticas para completar el mercado de capitales, atraer inversiones extranjeras hacia sectores nuevos que puedan adquirir ventajas comparativas, y mejorar la infraestructura física y social, así como la aplicación de un programa de capacitación laboral eficaz y la negociación del acceso de productos específicos a mercados también específicos.

La puesta en práctica de una apertura dinamizadora del desarrollo significará corregir las posiciones liberalizadoras a ultranza adoptadas en años recientes. Ciertamente exigirá ajustes más realistas a las políticas que se vienen aplicando en muchos países.

El ajuste de la política comercial deberá ir acompañado por una valoración mayor del papel que le corresponde al tipo de cambio en el logro de la transformación productiva. Parece imposible orientar decididamente al sector privado hacia la producción de bienes transables internacionalmente si no se mantiene un tipo de cambio favorable y también estable en el tiempo (es decir, independiente de condiciones economicas pasajeras). Es preciso que las autoridades económicas de la región presten mayor atención a las políticas económicas necesarias para lograr este objetivo, una de las cuales ha de ser la regulación de las corrientes internacionales de capital de corto plazo.

Para el éxito de la apertura es condición fundamental que el marco internacional sea propicio. Sin la eliminación del proteccionismo en los países centrales, la apertura se debilita gravemente como opción de política, no ya para un número limitado de países (como en el este asiático en los affos sesenta), sino para un conjunto amplio de países que la realizan al mismo tiempo.

Bibliografia

Agosin, M. R. (1992): Polf́tica comercial en los países dinámicos de Asia: aplicaciones a América Latina, trabajo preparado para la CEPAL, Santiago de Chile, mimeo.

Agosin, M. R., R. Fuentes y L. Letelier (1993): Los capitales extranjeros en las economias latinoamericanas: el caso de Chile, Washington D.C., Banco Interamericano de Desarrollo (BID) / Red de Centros de Investigación Aplicada.
Akyúz, Y. (1993): Does financial liberalization improve trade performance?, M. R. Agosin y D. Tussie, (eds.), Trade and Growth: New Dilemmas in Trade Policy, Basingstoke, Inglaterra, Macmillan.

Amsden, A. H. (1993): Trade Policy and Economic Performance in South Korea, en M. R. Agosin y D. Tussie, (eds.), Trade and Growth: New Dilemmas in Trade Policy, Basingstoke, Inglaterra, Maemillan. 
Ariff, M. y H. Hill (1989): Export Oriented Industrialization: The ASEAN Experience, Londres, Allen and Unwin.

Calvo, G., E. Leiderman y C. Reinhart (1993): Capital inflows and real exchange rate appreciation in Latin America: the role of external factors, IMF Staff Papers, vol. 40, No 1, Washington, D. C., Fondo Monetario Internacional (FMI), marzo.

Cárdenas, M. y F. Barrera (1993): Efectos macroeconómicos de los capilales extranjeros: el caso colombiano, Washington, D.C., BID/Red de Centros de Investigación Aplicada.

CEPAL (Comisión Económica para América Latina y el Caribe) (1992a): La política cambiaria en América Latina a comienzos de los años noventa (LC/R. 1193), Santiago de Chile, septiembre.

(1992b): Balance preliminar de la economia de América Latina y el Caribe, 1992 (LC/G. 1751), Santiago de Chile, diciembre.

(1992c): Equidad y transformación productiva: un enfoque integrado (LC/G. 1701 (SES.24/4)), Santiago de Chile, 6 de febrero.

(1993): Anuario estadístico de América Latina y el Caribe, edicion 1992, Santiago de Chile. Publicación de las Naciones Unidas, $\mathrm{N}^{\circ}$ venta S.93.II,G.1.

Damill, M. y S, Keifman (1992): Liberalización del comercio en una economía de alta inflacion: Argentina 1989-91, Pensamiento iberoamericano, $\mathbf{N}^{\circ} 21$, Madrid, Instituto de Cooperación Iberoamericana (ICI)/CEPAL, enero-junio.

Díaz-Alejandro, C. F. (1985): Good-bye financial repression, hellow financial crash, Journal of Development Economics, $\mathrm{N}^{\mathrm{a}}$ 19, Amsterdam, Elsevier Science Publishers B,V, (North Holland), diciembre.

Edwards, S. (1989): The order of liberalization of the current and capital accounts of the balance of payments, Essays in International Finance, $\mathrm{N}^{\mathrm{D}}$ 156, Princeton N. J., Princeton University Press.

Ffrench-Davis, R. (1986): Import liberalization: the Chilean experience, 1973-82, S. Valenzuela y A. Valenzuela (eds.), Military rule in Chile, Baltimore, Johns Hopkins University Press.

Ffrench-Davis, R. y O. Muñoz (1990): Desarrollo económico, inestabilidad y desequilibrios políticos en Chile: $1950-89$, Colección Estudios CIEPILAN, No 28, Santiago de Chile, Corporación de Investigaciones Económicas para América Latina (CIEPLAN), junio.

Ffrench-Davis, R,, P. Leiva y R. Madrid (1991): La apertura comercial en Chlle: experiencias y perspectivas, Estudios de política comercial $\mathrm{N}^{\circ} 1$, Ginebra, Conferencia de las Naciones Unidas sobre Comercio y Desarrollo (UNCTAD).

Fritsch, W. y G. Franco (1993): The political economy of trade and industrial policy reform in Brazil in the 1990s, trabajo preparado para la CEPAL, mimeo.

Herrera, C. (1992); La apertura gradual en Costa Rica a partir de 1983, Pensamiento Iberoamericano, $\mathrm{N}^{\circ} 21$, Madrid, ICJ/CEPAL, enero-junio.

Katz, J. (1993): Una interpretación del proceso de desarrollo industrial de la Argentina, Santiago de Chile, CEPAL, marzo, mimeo.
Lahera, E. (1992): Convergencia de los esquemas de integración (LC/R. 1192), Santiago de Chile, CEPAL, octubre.

Meller, P. (1992): Economía política de la apertura comercial chilena, Santiägo de Chile, CEPAL, diciembre, mimeo.

Mizala, A. (1992): Chile, Argentina y Brasil: perspectivas de la integración económica, A. Butelman y P. Meller (eds.), Estrategia comercial chilena para la década del 90 , Santiago de Chile, CIEPLAN.

Morales, J. A. (1992): Reformas estructurales y crecimiento eco nómico en Bolivia, J. Vial (ed.), Addónde va América Latina? Balance de las reformas económicas, Santiago de Chile, CIEPLAN

Noland, M. (1990): Pacific Basin Developing Countries- Prospects for the Future, Washington, D.C., Institute for International Economics (IIE).

Ocampo, J. A. (1990): La apertura externa en perspectiva, F. Gómez (ed.), Apertura económica y sistema financiero, Bogotá, Asociación Cambiaria de Colombia.

Ocampo, J. A. y L. Villar (1992): Trayectoria y vicisitudes de la apertura económica colombiana, Pensamiento iberoamerica$n o, \mathrm{~N}^{\circ} 21$, Madrid, ICI/CEPAL, enero-junio.

Rodrik, D. (1992): Conceptual issues in the design of trade policy for industrialization, World Development, Vol. 20, $\mathrm{N}^{\circ} 3$, Nueva York, Pergamon Press, junio.

Ros, J. (1992); La reforma del régimen comercial en México durante los años ochenta: sus efectos economicos y dimensiones políticas, Conyuntura economica latinoamericana, Vol. 22, $\mathrm{N}^{\circ}$ 3, Seminario Regional sobre Reformas de Política Pública, Bogotá, Fundación para la Educación Superior y el Desarrollo (FEDESARROLLO), octubre.

Sachs, J. D. (1987): Trade and Exchange Rate Policies in Growth-oriented Adjustment Programs, Symposium on Growth-Oriented Adjustment Programs, Washington, D.C. Fondo Monetario Internacional (FMI)/Banco Mundia], 25 al 27 de febrero

Ten Kate, A. (1992): El ajuste estructural de México. Dos historias diferentes, Pensamiento iberoamericano, $\mathrm{N}^{\circ} 21$, Madrid, ICI/ CEPAL, enero-junio.

Wade, R. (1990a): Industrial policy in East Asia: does it lead or follow the market?, en G. Gereffi y D. Wyman (eds.), Ma nufacturing Miracles - Paths of Industrialization in Latin America and East Asia, Princeton N.J., Princeton University Press.

(1990b): Governing the Market - Economic Theory and the Role of Government in East Asian Industrialization, Princeton N.J., Princeton University Press.

Westphal, L. E. (1992): La política industrial en una economía impulsada por las exportaciones: lecciones de la experiencia de Corea del Sur, Pensamiento iberoamericano, $\mathrm{N}^{\mathrm{D}} 21$, Madrid, ICI/CEPAL, enero-junio.

Williamson, J. (1992): Acerca de la liberalización de la cuenta de capitales, Estudios de Economia, vol, 19, $\mathrm{N}^{\circ} 2$, Santiago de Chile, Universidad de Chile, Facultad de Ciencias Fconómicas y Administrativas, Departamento de Economía. 